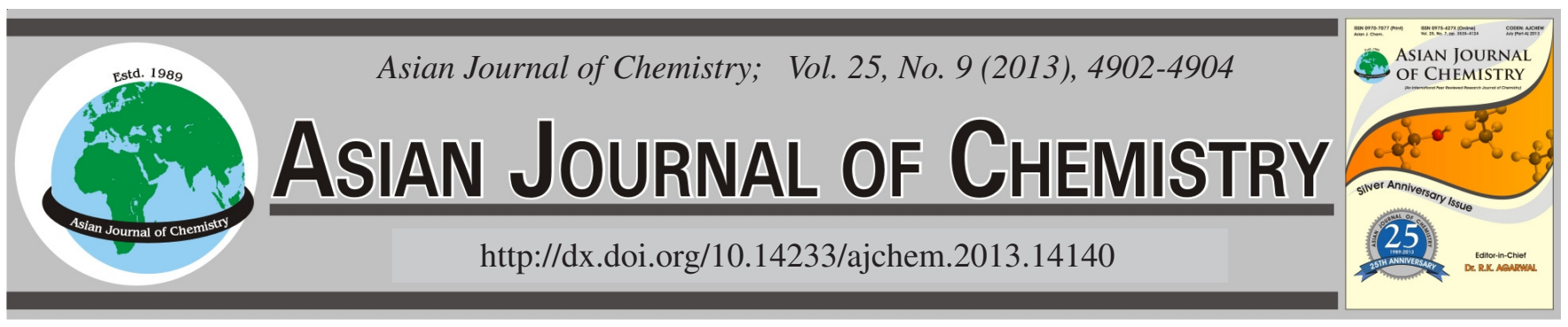

\title{
Isolation and Characterization of a New Allelochemical from Seeds of Adenanthera pavonina Linn.
}

\author{
R.N. YADAVA* and UMESH KUMAR ViSHWAKARMA
}

Natural Products Laboratory, Department of Chemistry, Dr. H.S. Gour Central University, Sagar-470 003, India

*Corresponding author: E-mail: rnyadava@rediffmail.com; umesh.chemistry@gmail.com

A new allelochemical (1), m.p. $282-284^{\circ} \mathrm{C}$, m.f. $\mathrm{C}_{31} \mathrm{H}_{36} \mathrm{O}_{19}$, [M] ${ }^{+} 712$ (FABMS), has been isolated from methanolic extract of the seeds of Adenanthera pavonina Linn. alongwith two known compounds 2',4'7-trihydroxy isoflavone and isovitexin. The structure of a new compound was characterized as 3,5,7,3',4'-pentahydroxy flavone-3'-O- $\alpha$-L-rhamnopyranosyl-( $1 \rightarrow 4)$-O- $\alpha$-L-arabinopyranosyl-( $1 \rightarrow 3$ )-

$\mathrm{O}-\beta$-D- xylopyranoside, by various colour reactions, spectral analysis and chemical degradations.

Key Words: Adenanthera pavonina Linn., Leguminosae, Allelochemical.

\section{INTRODUCTION}

Adenanthera pavonina Linn. belongs to family Leguminosae. It is commonly known as "Barigumchi" in Hindi. It is found in Bengal, Burma, Eastern sub-Himalayan tract, often planted along roadsides, especially in South India. Its seeds are used for treatment of cholera and general paralysis. Decoction of seeds, in pulmonary affections and externally applied in chronic opthalmia. A decoction is made from the leaves in South India and given as a remedy for chronic rheumatism and gout. Its decoction is said to be an aphrodisiac. This decoction is said to be useful in haemorrhage from the bowels and haematuria ${ }^{1,2}$. Earlier workers ${ }^{3-7}$ have reported various chemical constituents from this plant. In the present paper we report the isolation and structural elucidation of a new allelochemical 3,5,7,3',4'-pentahydroxy flavone-3'-O- $\alpha$-Lrhamnopyranosyl-( $1 \rightarrow 4)-\mathrm{O}-\alpha-\mathrm{L}$-arabinopyranosyl-( $1 \rightarrow 3)-\mathrm{O}-$ $\beta$-D-xylopyranoside (1) alongwith two known compounds 2,4,7-trihydroxyisoflavone (2) and isovitexin (3) from methanolic extract of the seeds of this plant.

\section{EXPERIMENTAL}

All of the melting points were determined on a thermoelectrical melting point apparatus and are uncorrected. The IR spectra were recorded in $\mathrm{KBr}$ disc on FT-IR spectrometer Shimadzu $8201 \mathrm{PC}\left(4000-400 \mathrm{~cm}^{-1}\right) .{ }^{1} \mathrm{H}$ and ${ }^{13} \mathrm{C}$ NMR spectra were recorded at $300 \mathrm{MHz}$ using solvent $\mathrm{CDCl}_{3}$ and TMS as internal standard on Bruker DRX-300 spectrometer. UV spectra were recorded in $\mathrm{MeOH}$ (Shimadzu UV 1800 spectrophotometer) and mass spectra on a Jeol D-300 mass spectrometer.

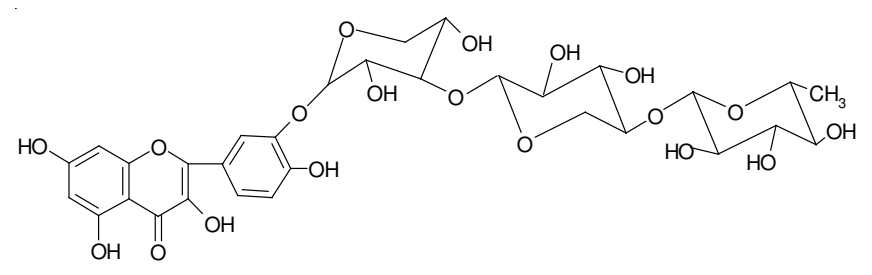

Compound 1<smiles>O=c1c(O)c(-c2ccc(O)c(O)c2)oc2cc(O)cc(O)c12</smiles><smiles>O=c1c(-c2ccc(O)cc2O)coc2cc(O)ccc12</smiles>

Compound 2<smiles>O=c1cc(-c2ccc(O)cc2)oc2cc(O)c(C(O)OC3C(O)C(O)C(O)C3O)c(O)c12</smiles>

Compound 3 
Plant material: The seeds of the plant were collected locally around sagar region and were taxonomically authenticated by taxonomist, Department of Botany, Dr. H.S. Gour Central University, Sagar (M.P.) India. A voucher specimen has been deposited in the Natural Products Laboratory, Department of Chemistry of this university.

Extraction and isolation: Air dried powdered seeds $(3 \mathrm{~kg})$ of the plant were extracted with petroleum ether (40$60{ }^{\circ} \mathrm{C}$ ) in a Soxhlet apparatus for $74 \mathrm{~h}$. The defatted seeds of the plant were further exhaustively partitioned with chloroform, ethyl acetate, acetone and methanol. The methanol soluble fraction was further concentrated under reduced pressure to yield brown viscous mass $(1.80 \mathrm{~g})$, which was subjected to TLC examination using nBAW (4:1:5) as eluent and $I_{2}$ vapours as visualizing agent. It gave three spots indicating it to be a mixture of three compounds $\mathbf{1 , 2}$ and $\mathbf{3}$. These compounds were separated by TLC and purified by column chromatography over silica gel $\mathrm{G}$ using $\mathrm{CHCl}_{3}: \mathrm{MeOH}$ (4:8) as eluent and studied separately.

Study of compound 1: It was crystallized from acetone to yield 1.15 g. It has m.p. $282-284{ }^{\circ} \mathrm{C}$, m.f. $\mathrm{C}_{31} \mathrm{H}_{36} \mathrm{O}_{19},[\mathrm{M}]^{+}$ 712 (FABMS); found (\%): C 52.10, H 5.02, calcd. (\%) for m.f. $\mathrm{C}_{31} \mathrm{H}_{36} \mathrm{O}_{19}$ : C 52.25, H 5.06; UV $\lambda_{\max } \mathrm{MeOH}$ (nm): 256, $365 ;\left(+\mathrm{AlCl}_{3}-\mathrm{HCl}\right) 266,356$; (+NaOAc) 272, 362; IR ( KBr, $\left.v_{\max }, \mathrm{cm}^{-1}\right): 3480,2906,1642,1626,1584,1062,926$ and 854 ; ${ }^{1} \mathrm{H}$ NMR $\left(300 \mathrm{MHz}, \mathrm{CDCl}_{3}\right), \delta(\mathrm{ppm}) ; 6.15(1 \mathrm{H}, \mathrm{d} J=2.1 \mathrm{~Hz}$, H-6), 6.34 (1H, d J = 2.1 Hz, H-8), 9.34 (1H, s, 3-OH), 12.45 $(1 \mathrm{H}, \mathrm{s}, 5-\mathrm{OH}), 10.68(1 \mathrm{H}, \mathrm{s}, 7-\mathrm{OH}), 7.70(1 \mathrm{H}, \mathrm{d}, J=2.2 \mathrm{~Hz}$, H-2'), $6.84\left(1 \mathrm{H}, \mathrm{d}, J=8.6 \mathrm{~Hz}, \mathrm{H}-5^{\prime}\right), 7.65(1 \mathrm{H}, \mathrm{dd}, J=8.2,2.4$ Hz, H-6'), 9.32 (1H, s, 4'-OH), 5.33 (1H, d, $J=7.5$ Hz, H-1"), $3.93(1 \mathrm{H}, \mathrm{dd}, J=8.0,8.3 \mathrm{~Hz}, \mathrm{H}-2 "), 4.10(1 \mathrm{H}, \mathrm{d}, J=8.3 \mathrm{~Hz}$, H-3"), 4.15 (1H, s, H-4"), 3.72 (2H, d, $J=9.9$ Hz, H-5"), 5.24 $\left(1 \mathrm{H}, \mathrm{d}, J=5.1 \mathrm{~Hz}, \mathrm{H}-1{ }^{\prime \prime}\right), 3.72(1 \mathrm{H}, \mathrm{dd}, J=8.4,4.9 \mathrm{~Hz}, \mathrm{H}-$ 2"'), 3.52 (1H, dd, $J=6.8,3.1 \mathrm{~Hz}, \mathrm{H}-3$ "'), 3.61 (1H, m, H-4"'), $3.51\left(2 \mathrm{H}, \mathrm{d}, J=3.6 \mathrm{~Hz}, \mathrm{H}-5^{\prime \prime \prime}\right), 4.51(1 \mathrm{H}, \mathrm{d}, J=1.6 \mathrm{~Hz}, \mathrm{H}-$ 1"'), 3.18-3.68 (4H, m, H-2"'", H-3"'", H-4"'", H-5"'"), 1.10 (3H, $\left.\mathrm{d}, J=5.9 \mathrm{~Hz}, \mathrm{CH}_{3}-6 " '\right)$. ${ }^{13} \mathrm{C} \mathrm{NMR}\left(300 \mathrm{MHz}, \mathrm{CDCl}_{3}\right)$, "(ppm): 146.8 (C-2), 137.4 (C-3), 177.6 (C-4), 163.0 (C-5), 99.5 (C-6), 164.9 (C-7), 95.2 (C-8), 158.6 (C-9), 104.2 (C-10), 125.2 (C-1'), $114.0\left(\mathrm{C}-2^{\prime}\right), 147.0\left(\mathrm{C}-3^{\prime}\right), 148.6\left(\mathrm{C}-4^{\prime}\right), 115.2$ (C-5'), 120.4 (C-6'), 105.0 (C-1"), 75.8 (C-2"), 76.3 (C-3"), 72.2 (C-4"), 66.8 (C-5"), 107.4 (C-1"'), 83.0 (C-2"'), 76.2 (C-3"'), 86.1 (C-4"'), 59.9 (C-5"'), 101.8 (C-1"'"), 72.4 (C-2"''), 72.8 (C-3"'"), 74.0 (C-4'"'), 72.7 (C-5'"'), 18.4 (C-6"'") and [M] ${ }^{+}$ 712 (FABMS).

Acid hydrolysis of compound 1: Compound 1 (50 mg) was dissolved in ethanol $(15 \mathrm{~mL})$ and refluxed with $20 \mathrm{~mL}$ of $\mathrm{H}_{2} \mathrm{SO}_{4}$ on water bath for 6-8 h. The reaction mixture was concentrated and allowed to cool and residue was extracted with diethyl ether $\left(\mathrm{Et}_{2} \mathrm{O}\right)$. The ethereal layer was washed with water and evaporated to dryness. The residue was subjected to column chromatography over silica gel column using $\mathrm{CHCl}_{3}$ : $\mathrm{MeOH}(3: 6)$ to give compound $\mathbf{1 - A}$, identified as 3,5,7,4'tetrahydroxy flavone by comparison of its spectral data with reported literature values. The aqueous hydrolyzate was neutralized with $\mathrm{BaCO}_{3}$ and $\mathrm{BaSO}_{4}$ filtered off. The filtrate was concentrated and subjected to paper chromatography examination using nBAW (4:1:5) solvent and aniline hydrogen phthalate as spraying reagent, showed the presence of Lrhamnose $\left(R_{f} 0.36\right)$, L-arabinose $\left(R_{f} 0.22\right)$ and D-xylose $\left(R_{f}\right.$ 0.27) (Co-PC).

Study of compound 1-A: It has m.f. $\mathrm{C}_{15} \mathrm{H}_{10} \mathrm{O}_{7}$, m.p. 313$315^{\circ} \mathrm{C},[\mathrm{M}]^{+} 302$ (EIMS); found (\%): C 59.52, H 3.25, calcd. (\%) for m.f. $\mathrm{C}_{15} \mathrm{H}_{10} \mathrm{O}_{7}, \mathrm{C} 59.60, \mathrm{H} 3.31$; UV: $\lambda_{\max }(\mathrm{nm})$ : $(\mathrm{MeOH})$ 255, 371; $\left(+\mathrm{AlCl}_{3}\right)$ 272, 450; $\left(+\mathrm{AlCl}_{3} / \mathrm{HCl}\right)$ 268, 359, 428; (+NaOAc) 265, 358; IR (KBr, $\left.v_{\max }, \mathrm{cm}^{-1}\right): 3472,2902,1638$, 1623, 1580, 1060, 923 and 852; ${ }^{1} \mathrm{H}$ NMR $\left(300 \mathrm{MHz}, \mathrm{CDCl}_{3}\right)$ $\delta$ (ppm): $6.12(1 \mathrm{H}, \mathrm{d}, J=2.3 \mathrm{~Hz}, \mathrm{H}-6), 6.31(1 \mathrm{H}, \mathrm{d}, J=1.9$ $\mathrm{Hz}, \mathrm{H}-8), 9.32$ (3-OH), 12.42 (5-OH), 10.70 (7-OH), $7.76(1 \mathrm{H}$, $\left.\mathrm{d}, J=2.2 \mathrm{~Hz}, \mathrm{H}-2^{\prime}\right), 6.82\left(1 \mathrm{H}, \mathrm{d}, J=8.4 \mathrm{~Hz}, \mathrm{H}-5^{\prime}\right), 7.58(1 \mathrm{H}$, dd, $\left.J=7.7,2.1 \mathrm{~Hz}, \mathrm{H}-6^{\prime}\right), 9.60$ ( $\left.3^{\prime}-\mathrm{OH}\right), 9.33$ (4'-OH). ${ }^{13} \mathrm{C}$ NMR (300 MHz, $\left.\mathrm{CDCl}_{3}\right) \delta$ (ppm): $148.9(\mathrm{C}-2), 136.1$ (C-3), 176.2 (C-4), 162.8 (C-5), 98.4 (C-6), 166.0 (C-7), 95.1 (C-8), 159.1 (C-9), 104.6 (C-10), 124.6 (C-1'), 115.8 (C-2'), 147.0 (C-3'), 149.1 (C-4'), 115.8 (C-5'), 120.1 (C-6').

Permethylation of compound 1: Compound $\mathbf{1}(25 \mathrm{mg}$ ) was refluxed with $\mathrm{CH}_{3} \mathrm{I}(5 \mathrm{~mL})$ and $\mathrm{Ag}_{2} \mathrm{O}(15 \mathrm{~mL})$ in $\mathrm{DMF}$ $(20 \mathrm{mg})$ for two days and then filtered. The filtrate was hydrolyzed with $10 \%$ ethanolic $\mathrm{H}_{2} \mathrm{SO}_{4}$ for 5-6h, to give methylated aglycone, identified as 3'-hydroxy-3,5,7,4'-tetramethoxy flavone and methylated sugars, which were identified as 2,4-di-O-methylD-xylose $\left(\mathrm{R}_{\mathrm{G}} 0.65\right), 2,3$-di-O-methyl-L-arabinose $\left(\mathrm{R}_{\mathrm{G}} 0.63\right)$ and 2,3,4-tri-O-methyl- L-rhamnose $\left(\mathrm{R}_{\mathrm{G}} 1.02\right)$.

Enzymatic hydrolysis of compound 1: Compound 1 (15 $\mathrm{mg})$ was dissolved in $\mathrm{MeOH}(10 \mathrm{~mL})$ and hydrolyzed with equal volume of takadiastase. The reaction mixture was allowed to stay at room temperature for $48 \mathrm{hrs}$ and filtered. The proaglycone and hydrolysate were studied separately.

The hydrolyzate was concentrated and subjected to paper chromatography examination using nBAW (4:1:5) as solvent, which showed the presence of L-arabinose $\left(R_{f} 0.22\right)$ and Lrhamnose $\left(\mathrm{R}_{\mathrm{f}} 0.36\right)$ (Co-PC). The proaglycone was dissolved in $\mathrm{MeOH}(20 \mathrm{~mL})$ and further hydrolyzed with equal volume of almond emulsin at room temperature as usual procedure yielded aglycone, identified as 3,5,7,4'-tetrahydroxy flavone and sugar was identified as D-xylose $\left(\mathrm{R}_{\mathrm{f}} 0.27\right)(\mathrm{Co}-\mathrm{PC})$.

Study of compound 2: It has m.f. $\mathrm{C}_{15} \mathrm{H}_{10} \mathrm{O}_{5}$, m.p. 272$274^{\circ} \mathrm{C},[\mathrm{M}]^{+} 270$ (EIMS); found (\%), C 65.80, H 3.53, calcd. (\%) for m.f. $\mathrm{C}_{15} \mathrm{H}_{10} \mathrm{O}_{7}, \mathrm{C} 66.67, \mathrm{H} 3.70$; IR (KBr, $\left.v_{\max }, \mathrm{cm}^{-1}\right)$ : $3416,1616,1571,1502,1460 .{ }^{1} \mathrm{H}$ NMR $\left(30 \mathrm{MHz}, \mathrm{CDCl}_{3}\right): \delta$ (ppm) 8.15 (1H, s, H-2), 7.99 (1H, d, J = 8.6 Hz, H-5), 6.98 $(1 \mathrm{H}, \mathrm{dd}, J=8.2,2.4 \mathrm{~Hz}, \mathrm{H}-6), 7.10(1 \mathrm{H}, \mathrm{d}, J=2.3 \mathrm{~Hz}, \mathrm{H}-8)$, $\left.6.54(1 \mathrm{H}, \mathrm{d}, J=2.6 \mathrm{~Hz}, \mathrm{H}-3)^{\prime}\right), 6.30(1 \mathrm{H}, \mathrm{dd}, J=8.1,2.6 \mathrm{~Hz}$, H-5'), $6.87\left(1 \mathrm{H}, \mathrm{d}, J=8.0 \mathrm{~Hz}, \mathrm{H}-6^{\prime}\right)$,. Thus it was identified as 2',4',7-trihydroxy isoflavone.

Study of compound 3: It has m.f. $\mathrm{C}_{21} \mathrm{H}_{20} \mathrm{O}_{10}$, m.p. 236$238^{\circ} \mathrm{C},[\mathrm{M}]^{+} 432$ (EIMS); found (\%), C 58.10, H 4.58, calcd. (\%) for m.f. $\mathrm{C}_{21} \mathrm{H}_{20} \mathrm{O}_{10}, \mathrm{C} 58.33, \mathrm{H} 4.63$, UV: $\lambda_{\max } \mathrm{nm}:(\mathrm{MeOH})$ 266, 306, 332; IR (KBr, $\left.v_{\max }, \mathrm{cm}^{-1}\right)$ : 3730, 3400, 1658, 1630, 1610, 1500, 1362, 1190, 837, 780, 616, 560; ${ }^{1} \mathrm{H}$ NMR (300 $\left.\mathrm{MHz}, \mathrm{CDCl}_{3}\right): \delta(\mathrm{ppm}) 13.4(1 \mathrm{H}$, brs, $5-\mathrm{OH}), 7.96(2 \mathrm{H}, \mathrm{d}, J=$ $8.8 \mathrm{~Hz}, \mathrm{H} 2$ ', 6'), 6.90 (2H, d, J = 8.4 Hz, H3', 5'), $6.72(1 \mathrm{H}, \mathrm{s}$, H-3), 6.52 (1H, s, H-8), 4.50 (1H, d, J=10.2 Hz, H-1"), 4.12 (1H, t, $J=10.2$ Hz, H-2"), 4.3-3.2 (H-3", H-4", H-5", H-6"); ${ }^{13} \mathrm{C} \mathrm{NMR}\left(300 \mathrm{MHz}, \mathrm{CDCl}_{3}\right): \delta 164.0(\mathrm{C}-2), 102.9(\mathrm{C}-3), 181.6$ (C-4), 162.0 (C-9), 157.0 (C-5), 109.6 (C-6), 162.8 (C-7), 95.0 
(C-8), 103.2 (C-10), 120.4 (C-1'), 126.5 (C-2', 6'), 115.3 (C3', 5'), 80.0 (C-1"), 72.6 (C-2"), 69.9 (C-3"), 68.2 (C-4"), 59.9 (C-6"). Thus it was identified as isovitexin.

\section{RESULTS AND DISCUSSION}

Chemical examination of methanolic extract of seeds of Adenanthera pavonina Linn., yielded a new compound 1. It has molecular formula $\mathrm{C}_{31} \mathrm{H}_{36} \mathrm{O}_{19}$, m.p. $282-284{ }^{\circ} \mathrm{C}$, [M] $]^{+} 712$ (FABMS). It gave Molisch and Shinoda tests ${ }^{8}$ showing its flavanoidal glycosidic nature. Its IR spectra showed strong absorption bands at 3480, 2906, 1642, 1626, 1584, 1062, 926 and $854 \mathrm{~cm}^{-1}$. In UV spectrum two bands at 256 and $356 \mathrm{~nm}$ showed its flavonoidal skeleton. The bathochromic shift of 23 $\mathrm{nm}$ with $\mathrm{AlCl}_{3}$ and $32 \mathrm{~nm}$ with $\mathrm{NaOAc}$ in band I revealed the presence of - $\mathrm{OH}$ groups at $\mathrm{C}-5$ and $\mathrm{C}-7$ positions in the aglycone $\mathbf{1 - A ^ { 9 , 1 0 }}$. Formation of 3,4-dihydroxy benzoic acid on alkaline degradation confirmed the presence of -OH groups at C-3' and C-4' positions in aglycone. In ${ }^{1} \mathrm{H}$ NMR spectrum, a singlet at $\delta 9.32$ confirmed the presence of -OH group at $\mathrm{C}-3$ position. Two meta-coupled doublets at $\delta 6.15(1 \mathrm{H}, \mathrm{d}, J=2.1 \mathrm{~Hz})$ and $\delta 6.34(1 \mathrm{H}, \mathrm{d}, J=2.1 \mathrm{~Hz})$ were assigned to $\mathrm{H}-6$ and $\mathrm{H}-8$ of $\mathrm{A}$ ring in the aglycone 1-A. An ortho-coupled doublet at $\delta 7.70$ $(1 \mathrm{H}, \mathrm{d}, J=2.2 \mathrm{~Hz})$ was assigned to $\mathrm{H}-2$ ' in ring B. In ${ }^{1} \mathrm{H}$ NMR spectrum, a meta-coupled doublet at $\delta 6.84(1 \mathrm{H}, \mathrm{d}, J=8.6$ $\mathrm{Hz})$ and an ortho-meta-coupled double- doublets at $\delta 7.65$ $(1 \mathrm{H}, \mathrm{dd}, J=8.2,2.4 \mathrm{~Hz})$ were assigned to $\mathrm{H}-5^{\prime}$ and $\mathrm{H}-6{ }^{\prime}$ in ring B. The anomeric proton signals at $\delta 5.33(1 \mathrm{H}, \mathrm{d}, J=7.5$ $\mathrm{Hz}), \delta 5.24(1 \mathrm{H}, \mathrm{d}, J=5.1 \mathrm{~Hz})$ and $\delta 4.51(1 \mathrm{H}, \mathrm{d}, J=1.6 \mathrm{~Hz})$ were assigned for H-1", H-1"' and H-1"'" of D-xylose, L-arabinose and L-rhamnose, respectively.

In the mass spectrum of the compound 1, characteristic ion peaks at m/z $712[\mathrm{M}]^{+}, 566\left[\mathrm{M}^{+}\right.$-L-rhamnose $], 434\left[\mathrm{M}^{+}-\mathrm{L}-\right.$ arabinose] and $302\left[\mathrm{M}^{+}\right.$-D-xylose, aglycone] were found by subsequent losses from the molecular ion of each molecule of L-rhamnose, L-arabinose and D-xylose revealing L-rhamnose as terminal sugar, L-arabinose as middle sugar and D-xylose was directly attached to -OH group at C-3' position of aglycone.

Acid hydrolysis of compound 1 with $10 \%$ ethanolic $\mathrm{H}_{2} \mathrm{SO}_{4}$ gave aglycone 1-A, m.p. $315-318{ }^{\circ} \mathrm{C}$, m.f. $\mathrm{C}_{15} \mathrm{H}_{10} \mathrm{O}_{7}$, $[\mathrm{M}]^{+} 302$ (EIMS). It was identified as 3,5,7,3',4'-pentahydroxy flavone by comparision of its spectral data with reported literature values ${ }^{11-14}$.

The aqueous hydrolyzate after the removal of aglycone was neutralized with $\mathrm{BaCO}_{3}$ and $\mathrm{BaSO}_{4}$ filtered off. The filtrate was concentrated and subjected to paper chromatography examination and sugars were identified as L-rhamnose $\left(\mathrm{R}_{\mathrm{f}}\right.$ $0.36)$, L-arabinose $\left(\mathrm{R}_{\mathrm{f}} 0.22\right)$ and $\mathrm{D}$-xylose $\left(\mathrm{R}_{\mathrm{f}} 0.27\right)(\mathrm{Co}-\mathrm{PC})^{15}$. Periodate oxidation of compound $\mathbf{1}$, confirmed that all the sugars were present in the pyranose form ${ }^{16}$.

The position of sugar moieties in compound $\mathbf{1}$ were determined by permethylation ${ }^{17}$ followed by acid hydrolysis, yielded methylated aglycone identified as 3'-hydroxy-3,5,7,4'tetramethoxy flavone showed that glycosylation was involved at C-3' position of the flavone and methylated sugars were identified as 2,4-di-O-methyl-D-xylose $\left(\mathrm{R}_{\mathrm{G}} 0.65\right)$, 2,3,di-Omethyl-L-arabinose $\left(\mathrm{R}_{\mathrm{G}} 0.63\right)$ and 2,3,4-tri-O-methyl-L-rhamnose $\left(\mathrm{R}_{\mathrm{G}} 1.02\right)$ indicating that $\mathrm{C}-1$ "'" of $\mathrm{L}$-rhamnose was linked to $\mathrm{C}-4$ "' of L-arabinose, $\mathrm{C}-1$ '" of L-arabinose was linked to C-
3" of D-xylose and C-1" of D-xylose was attached with C-3' position of the aglycone. Therefore it was concluded that interlinkages $(1 \rightarrow 4)$ between L-rhamnose and L-arabinose and $(1 \rightarrow 3)$ between L-arabinose and D-xylose were found which were further confirmed by ${ }^{13} \mathrm{C}$ NMR spectra.

Enzymatic hydrolysis of compound 1 with takadiastase liberated L-rhamnose $\left(\mathrm{R}_{\mathrm{f}} 0.36\right)$ first followed by L-arabinose $\left(\mathrm{R}_{\mathrm{f}} 0.22\right)$ and proaglycone 3,5,7,3',4'-pentahydroxy flavone3'-O- $\beta$-D-xylopyranoside confirming the presence of $\alpha$-linkage between L-rhamnose and L-arabinose as well as between Larabinose and D-xylose. Proaglycone on further hydrolysis with almond emulsin librated $D$ - xylose $\left(R_{\mathrm{f}} 0.27\right)$ suggesting the presence of $\beta$-linkage between $D$-xylose and aglycone. On the basis of above evidences the structure of compound $\mathbf{1}$ was characterized as 3,5,7,3',4'-pentahydroxyflavone-3'-O- $\alpha$ L-rhamnopyranosyl-(1"4)-O- $\alpha$-L-arabinopyranosyl-(1 $\rightarrow 3)$ O- $\beta$-D-xylopyranoside.

Compound 2 has m.p. $272-274{ }^{\circ} \mathrm{C}$, m.f. $\mathrm{C}_{15} \mathrm{H}_{10} \mathrm{O}_{5},[\mathrm{M}]^{+}$ 270 (EIMS). It was characterized as 2',4',7-trihydroxy isoflavone by comparision of its spectral data with reported literature values ${ }^{18}$.

Compound 3 has m.p. $236-238^{\circ} \mathrm{C}$, m.f. $\mathrm{C}_{21} \mathrm{H}_{20} \mathrm{O}_{10}$, [M] ${ }^{+}$ 432 (EIMS). It was identified as Isovitexin by comparision of its spectral data with reported literature values ${ }^{18,19}$.

\section{ACKNOWLEDGEMENTS}

The authors are thankful to the Head, RSIC (CDRI) Lucknow for recording various spectral data and Head, Department of Chemisty, Dr.H.S. Gour Central University, Sagar, India for providing necessary laboratory facilities.

\section{REFERENCES}

1. K.R. Kirtikar and B.D. Basu, Indian Medicinal Plants, Lalit Mohan Basu and Co., Vol. 2, pp. 908-910 (1975).

2 L.V. Asolkar, K.K. Kakkar and O.J. Chakre, Glossary of Indian Medicinal Plants with Active Principles, (A-K), 22 (2000).

3 M.S. Ali, F. Ahmed, I. Azhar and M.K. Pervez, Nat. Prod. Res., 19, 37 (2005).

4 S. Chandra, M. Verma and H. Saxena, Pharm. Biol., 20, 165 (1982).

5 S.K. Nigam, G. Mishra and C.R. Mishra, Planta Med., 23, 148 (1973).

6 I.S. Santos, A.E. Oliveira, C.M. Da, O.L. Machado, A.G. Neves-Ferreira, K.V. Fernandes, A.O. Carvalho, J. Perales and V.M. Gomes, Physiol. Plant, 131, 80 (2007).

7 M.L. Macedo, S.C. De, M.D. Freire and J.R. Parra, J. Agric. Food Chem., 52, 2533 (2004).

8 J. Shinoda, J. Pharm. Soc. (Japan), 48, 214 (1928).

9 T.J. Mabry, K.R. Markham and M.B. Thomas, The Systematic Identification of Flavonoids, Springer, New York, Vol. 51, p. 258 (1970).

10 A. Ulubelen, B.N. Timmermann and T.J. Mabry, Phytochemistry, 19, 905 (1980).

11 Z. Guvenalp and L.O. Demirezer, Turk. J. Chem., 29, 163 (2005).

12 S. Park, S. Yang, D. Ahn, J.H. Yang and D.K. Kim, J. Korean Soc. Appl. Biol.Chem., 54, 685 (2011).

13 J.X. Liu, D.L. Di and Y.P. Shi, J. Chin. Chem. Soc., 55, 863 (2008).

14 S. Saeidnia, N. Yassa, R. Rezaeipoor, A. Shafiee, A.R. Gohari, M. Kamlinejad and S. Goodarzy, Daru, 17, 37 (2009).

15 E. Lederer and M. Lederer, Chromatography, Elsevier Publishing Company, New York, 1, p. 247 (1957).

16 S. Hokomoni, J. Biochem., 66, 205 (1965).

17 F. Petek, Bull. Soc. Chem. Fr., 263 (1965).

18 H.S. Yoo, J.S. Lee, C.Y. Kim and J. Kim, Arch. Pharm. Res., 27, 544 (2004).

19 S. Othman, A.S. Hanzah, N. Aimi and N.H. Lajis, Pertanika J. Sci. Technol., 4, 183 (1996) 